\title{
Major Histocompatibility Class II Pathway Is Not Required for the Development of Nonalcoholic Fatty Liver Disease in Mice
}

\author{
Gilles Willemin, ${ }^{1}$ Catherine Roger, ${ }^{2}$ Armelle Bauduret, ${ }^{2}$ and Kaori Minehira ${ }^{1,3}$ \\ ${ }^{1}$ Department of Physiology, University of Lausanne, Rue du Bugnon 7, 1005 Lausanne, Switzerland \\ ${ }^{2}$ Center for Integrative Genomics, University of Lausanne, 1010 Lausanne, Switzerland \\ ${ }^{3}$ Nestlé Research Center, Vers-chez-les-Blanc, 1000 Lausanne 26, Switzerland \\ Correspondence should be addressed to Kaori Minehira; kaori.minehira@unil.ch
}

Received 12 February 2013; Accepted 22 March 2013

Academic Editor: Jun Ding

Copyright (C) 2013 Gilles Willemin et al. This is an open access article distributed under the Creative Commons Attribution License, which permits unrestricted use, distribution, and reproduction in any medium, provided the original work is properly cited.

\begin{abstract}
Single-nucleotide polymorphisms within major histocompatibility class II (MHC II) genes have been associated with an increased risk of drug-induced liver injury. However, it has never been addressed whether the MHC II pathway plays an important role in the development of nonalcoholic fatty liver disease, the most common form of liver disease. We used a mouse model that has a complete knockdown of genes in the MHC II pathway $\left(\mathrm{MHCII}^{\Delta / \Delta}\right)$. Firstly we studied the effect of high-fat diet-induced hepatic inflammation in these mice. Secondly we studied the development of carbon-tetra-chloride- $\left(\mathrm{CCl}_{4^{-}}\right)$induced hepatic cirrhosis. After the highfat diet, both groups developed obesity and hepatic steatosis with a similar degree of hepatic inflammation, suggesting no impact of the knockdown of MHC II on high-fat diet-induced inflammation in mice. In the second study, we confirmed that the $\mathrm{CCl}_{4}$ injection significantly upregulated the MHC II genes in wild-type mice. The $\mathrm{CCl}_{4}$ treatment significantly induced genes related to the fibrosis formation in wild-type mice, whereas this was lower in $\mathrm{MHCII}^{\Delta / \Delta}$ mice. The liver histology, however, showed no detectable difference between groups, suggesting that the MHC II pathway is not required for the development of hepatic fibrosis induced by $\mathrm{CCl}_{4}$.
\end{abstract}

\section{Introduction}

Major histocompatibility class II (MHC II) pathway plays an important role in immune function. The molecules of MHC II are expressed on the surface of antigen-presenting cells such as macrophages, B cells, and dendritic cells [1]. Once the processed antigen loaded onto MHC II molecules is presented on the surface of the cells, it promotes the $\mathrm{CD} 4+$ helper $\mathrm{T}$ cell recognition. This results in an immune response including the production of inflammatory cytokines [2]. Although the importance of the pathway has been widely studied in the immune processing, its specific roles on hepatic inflammation and fibrosis have not been clearly understood.

A genome-wide association study identified singlenucleotide polymorphisms (SNPs) in the MHC II pathway in lumiracoxib-treated patients that developed a liver injury [3]. The alleles of the genes (HLA-DRB1, 5,-DQB1, and -DQA1) had a strong association with elevated plasma liver enzymes in patients that developed the liver injury after the lumiracoxib treatment. Lumiracoxib, a selective cyclooxygenase-2 (COX-2) inhibitor, has been used for osteoarthritis and acute pain treatment $[4,5]$. The use of this COX-2 inhibitor is correlated with an increased risk of cardiovascular events and an acute hepatotoxicity $[6,7]$. However whether the MHC II pathway has been involved in the mechanism of these diseases has not been clarified.

A similar observation has been reported with a treatment of amoxicillin-clavulanate, an antimicrobial agent [8,9]. Again the SNPs in the region around HLA-DRB1 and HLADQB1 showed a strong association with the drug-induced liver injury. Interestingly, the alleles in HLA-DQB1 locus were also strongly associated with primary biliary cirrhosis [10], which is the most common autoimmune liver disease. During the development of biliary cirrhosis, $\mathrm{T}$ lymphocytes play an important role [11, 12], and a link between 


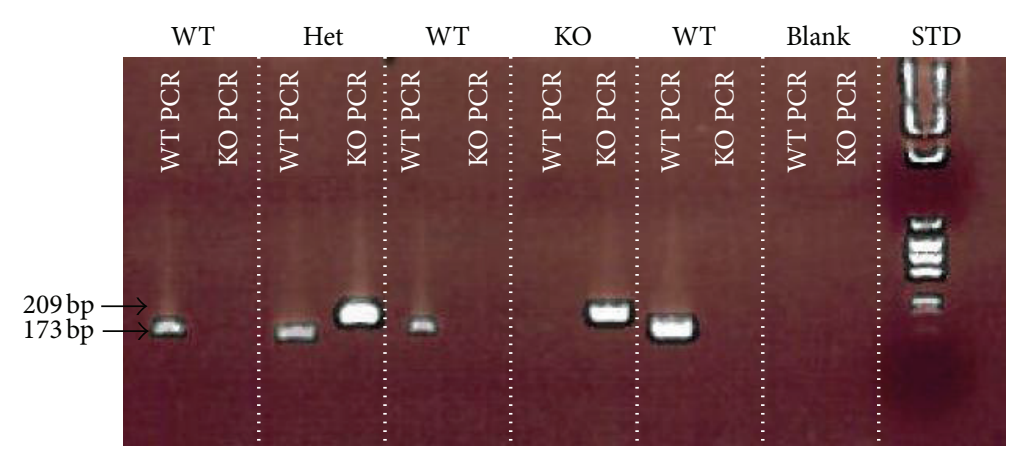

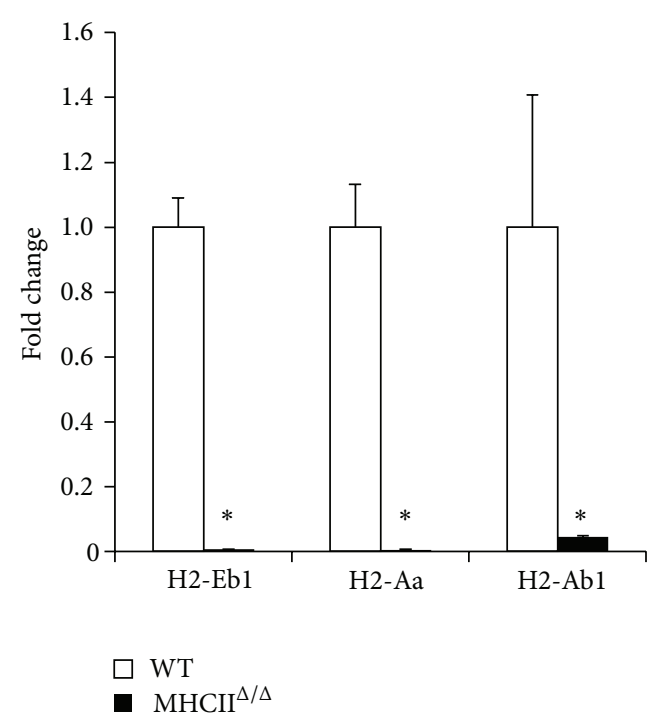

(b)

FIGURE 1: MHCII gene genotyping and hepatic expression in wild-type and MHCII ${ }^{\Delta / \Delta}$ mice. (a) Two different PCRs were performed for the detection of wild-type (WT PCR) and knockout (KO PCR: MHCII ${ }^{\Delta / \Delta}$ ) fragments; 173 bp for a WT band and 209 bp for a KO band. Therefore heterozygous (Het) presents both bands. (b) Gene expression of MHC II genes (H2-Eb1, -Aa, -Ab1) in liver samples by real-time RT-PCR. The expression was normalized by $\beta 2$ microglobulin and compared to the wild-type. Open bars represent wild-type and closed bars $\mathrm{MHCII}^{\Delta / \Delta}$ mice $\left(n=10-14\right.$ /group). Data are presented as mean \pm SEM. ${ }^{*}$ Significantly different from wild-type mice, $P<0.05$ (Student $t$-test).

the $\mathrm{T}$ lymphocytes hyperactivity and drug-induced liver injuries has been recently suggested [13]. In addition, several studies have demonstrated that the genes in the MHC II pathway were significantly upregulated in porcine-seruminduced hepatic fibrosis in rats $[14,15]$. These facts imply a strong influence of the MHC II pathway on the susceptibility to develop liver diseases.

Nonalcoholic fatty liver disease (NAFLD) is one of the major liver diseases in industrialized countries. Data are suggesting a strong increase of NAFLD prevalence in the next decades $[16,17]$. The disease consists of a diverse spectrum of liver pathologies, starting by hepatic steatosis and then steatohepatitis, a state of hepatic inflammation [18]. Then it progresses toward hepatic fibrosis, cirrhosis, and hepatic carcinoma. Although some molecular pathways that lead to hepatitis in NAFLD can also be activated in the drug-induced liver injuries, the implication of MHC II pathway has not been clearly understood in NAFLD model. Given the repeated reports on the association between alleles on MHC II genes and the susceptibility to a liver inflammation [3, 8-10], this pathway might play an important role in the development of NAFLD.

In the present study, we addressed whether the MHC II pathway might be required for hepatitis development and fibrosis formation. To this end, we chose to use a mouse model lacking all conventional genes in MHC II pathway [19]. The entire MHC II region ( $80 \mathrm{~kb}$ ) was deleted, resulting in the removal of the genes encoding the MHC II pathway $(\mathrm{H} 2-\mathrm{A} \beta$, $-\mathrm{A} \alpha,-\mathrm{E} \beta,-\mathrm{E} \beta 2$, and $-\mathrm{E} \alpha$ ). The mouse genes $\mathrm{H} 2-\mathrm{A} \beta$ and $-\mathrm{E} \beta$ have the closest homology to the human HLA-DQB1 gene. These mice are viable and fertile without major anatomical or physiological abnormalities [19]. We have studied whether these mice were protected against a high-fat diet-induced hepatitis and a chemical-induced hepatic fibrosis.

\section{Research Design and Method}

2.1. Animals, Diet, and Chemicals. B6;129S2-H2dlAb1-Ea $/ \mathrm{J}$ (strain $003584, \mathrm{MHCII}^{\Delta / \Delta}$ ) mice in which the $80 \mathrm{~kb}$ of MHC II region is deleted were purchased from Jackson Laboratories (Bar Harbor, ME, USA). These mice were bred with C57B6/J mice and the F2 generation was crossbred to obtain $\mathrm{MHCII}^{\Delta / \Delta}$ and wild-type mice. These mice were housed in ventilated cages at an animal facility of the University of Lausanne with 12-hour light and dark cycles and free access to food and water. Five-week-old male mice were subjected to high-fat diet (D12451, Research diets Inc., New Brunswick, NJ, USA) for 4 months. The dietary composition of the high-fat diet was carbohydrates $35 \%$, fat $45 \%$, and protein $20 \%$. Dietary protein was originated from casein, and fat was mainly from lard. All animal procedures used in this study were approved by the Swiss cantonal veterinary service.

Carbon tetrachloride $\left(\mathrm{CCl}_{4}\right)$, chloroform, methanol, EDTA, sirius red, and aprotinin were purchased from SigmaAldrich (Munich, Germany). Kits for measuring plasma alanine transaminase (ALT), aspartate transaminase (AST), and triglycerides (TG) were purchased from Wako Chemicals (Neuss, Germany). Hematoxylin \& eosin was purchased from Merck (Geneva, Switzerland). 


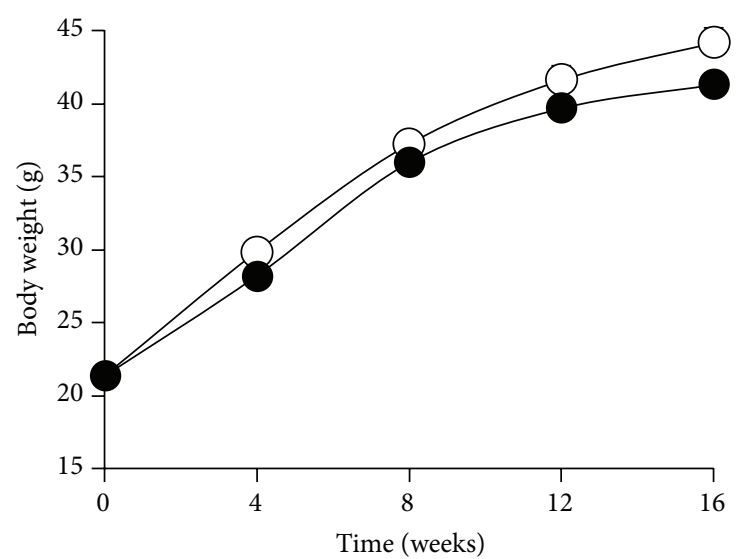

(a)

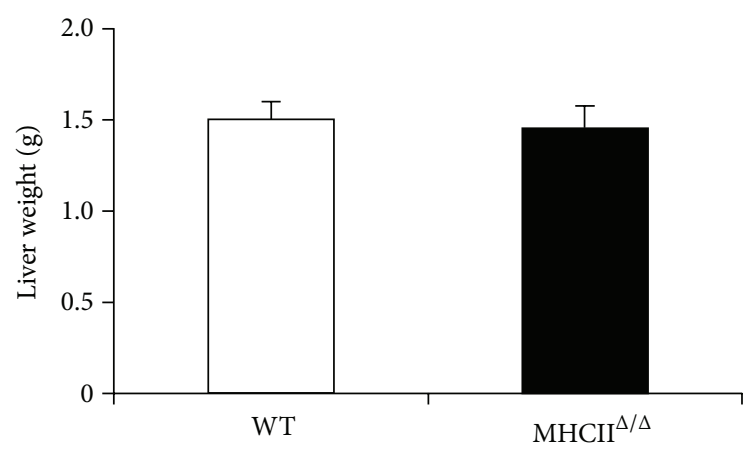

(c)

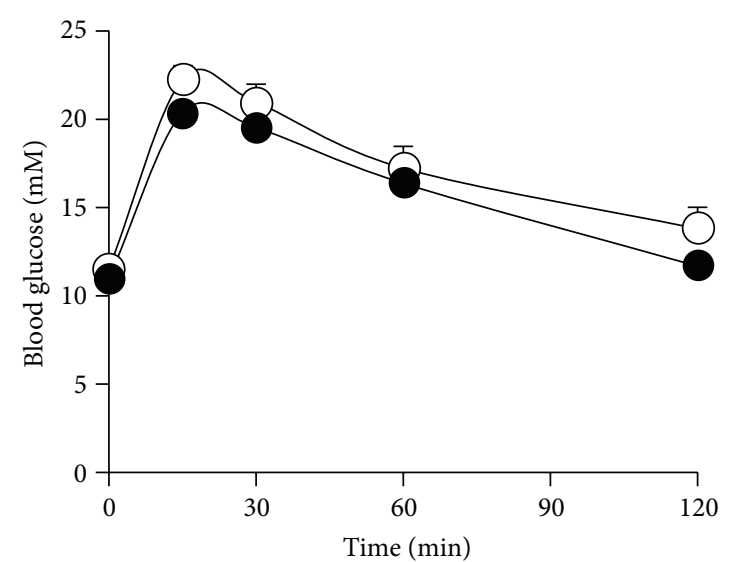

(b)

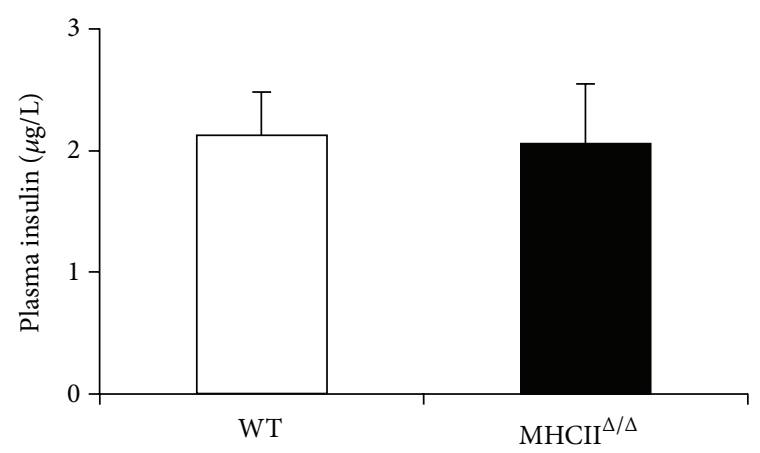

(d)

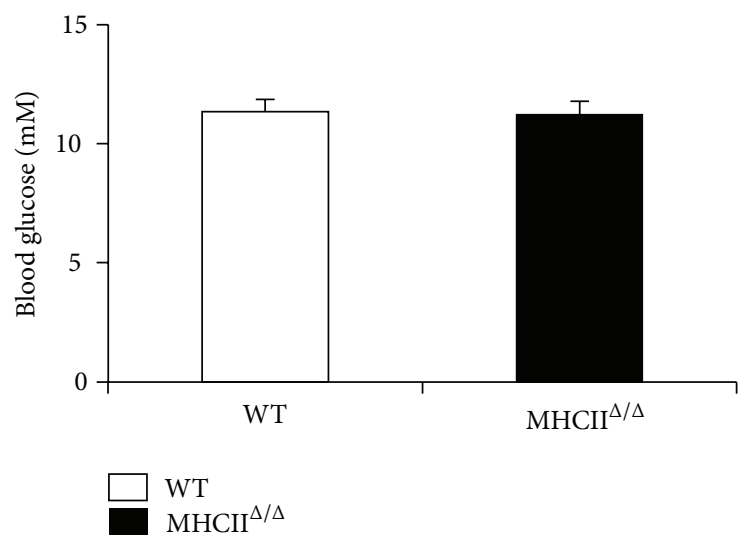

(e)

FIGURE 2: Effect of high-fat diet on metabolic parameters in wild-type and MHCII ${ }^{\Delta / \Delta}$ mice. Open circle/bars represent wild-type and closed circle/bars MHCII ${ }^{\Delta / \Delta}$ mice (wild-type: $n=25, \mathrm{MHCII}^{\Delta / \Delta}: n=20$ ). Data are presented as mean \pm SEM. (a) Body weight gain during 4-month diet. (b) Glucose tolerance test was performed around the 15th week of the intervention. (c) Liver weight at 16th week. (d) Fasting plasma insulin concentration at 16th week. (e) Fasting blood glucose concentration at 16th week.

2.2. High-Fat Diet Experiment. Five-week-old male $\mathrm{MHCII}^{\Delta / \Delta}$ mice and wild-type mice were assigned into the high-fat diet described above. Body weight was measured every month. A glucose tolerance test was performed around the 15th week of the intervention. Mice were fasted for 4 hours and a solution of $1 \mathrm{~g}$ of glucose per $\mathrm{kg}$ of mouse was injected intraperitoneally. Glycemia was monitored at 0,15 ,
30, 60, and 120 min using a glucometer (Bayer, Zurich, Switzerland).

At the end of the 4-month experiment, mice were fasted for 4 hours and glycemia was measured by a glucometer. Blood was collected by an intracardiac puncture and placed into a tube containing EDTA and aprotinin $(2 \mathrm{mM}$ and $0.1-$ 0.2 TIU, respectively) on ice. The plasma was then separated 


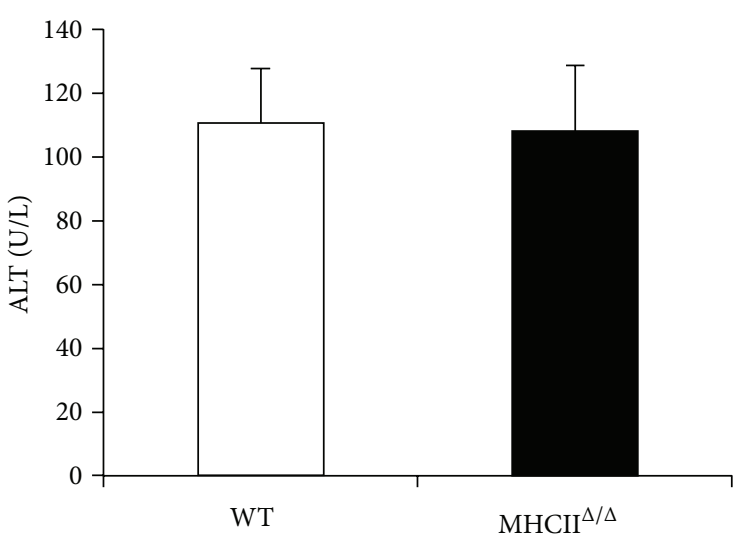

(a)

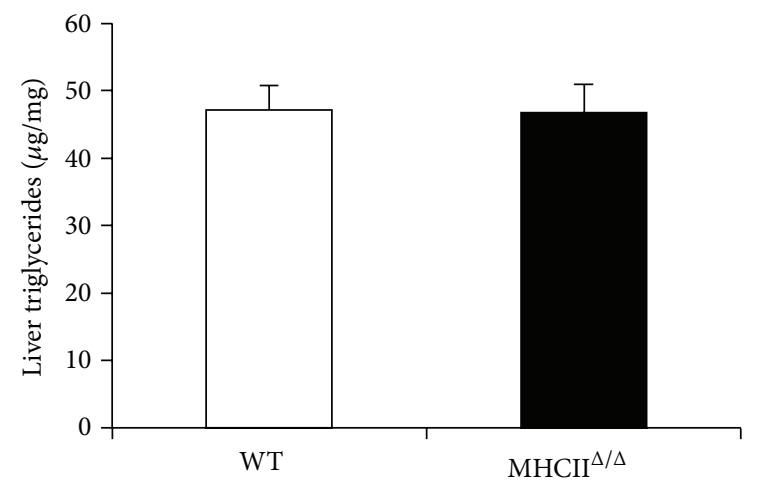

(c)

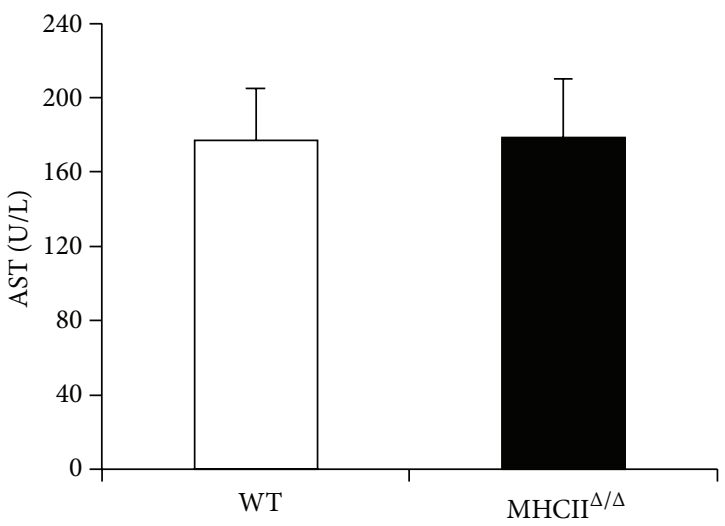

(b)

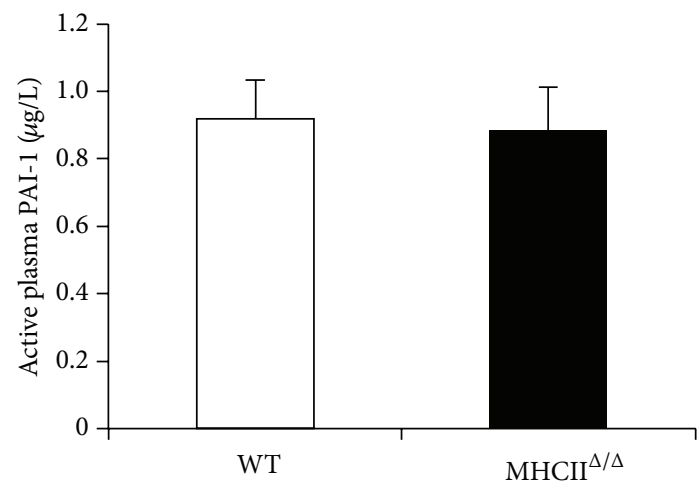

(d)

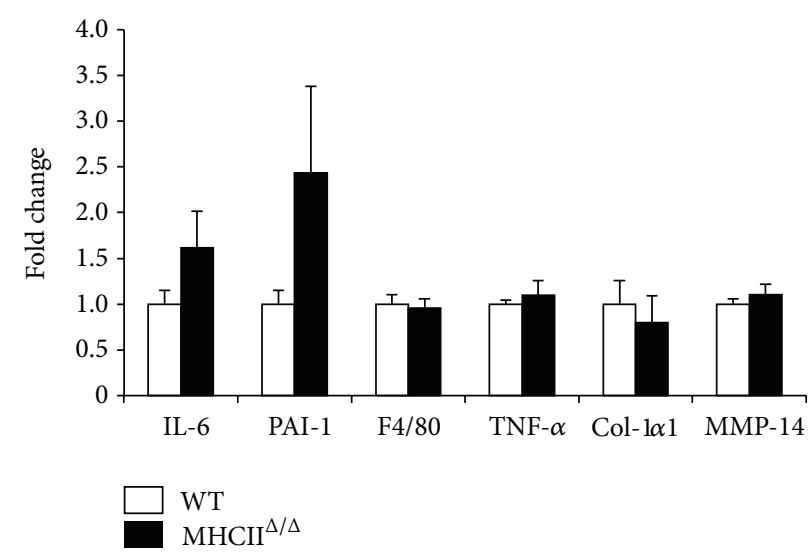

(e)

FIGURE 3: Effect of high-fat diet on liver enzymes, lipids, and inflammatory markers in wild-type and MHCII ${ }^{\Delta / \Delta}$ mice. Open bars represent wild-type and closed bars MHCII ${ }^{\Delta / \Delta}$ mice (wild-type: $n=25, \mathrm{MHCII}^{\Delta / \Delta}: n=20$ ). Data are presented as mean \pm SEM. (a) Plasma ALT level at 16th week. (b) Plasma AST level. (c) Liver triglyceride content at 16th week. (d) Fasting active plasma PAI-1 concentration at 16th week. (e) Gene expression related to inflammation and fibrogenesis in the liver at 16th week.

by centrifugation and stored at $-80^{\circ} \mathrm{C}$ until analysis. Liver and epididymal adipose tissues were harvested and weighed. The organs were flash-frozen into liquid nitrogen and stored at $-80^{\circ} \mathrm{C}$ until analysis.

2.3. $\mathrm{CCl}_{4}$ Treatment. To study the development of hepatic fibrosis, 8-week-old wild-type and $\mathrm{MHCII}^{\Delta / \Delta}$ male mice were treated by $1.25 \mu \mathrm{L} / \mathrm{g}$ body weight $\mathrm{CCl}_{4}$ ( $25 \%$ in sunflower oil) twice a week during 4 weeks. Another set of mice was treated by sunflower oil as control vehicle at the same time. Twenty hours following the last treatment, mice were fasted for 4 hours and anesthetized for a cardiac puncture. After sacrifice, blood and liver were kept for further analysis. Fresh liver pieces were put into $4 \%$ paraformaldehyde solution during 

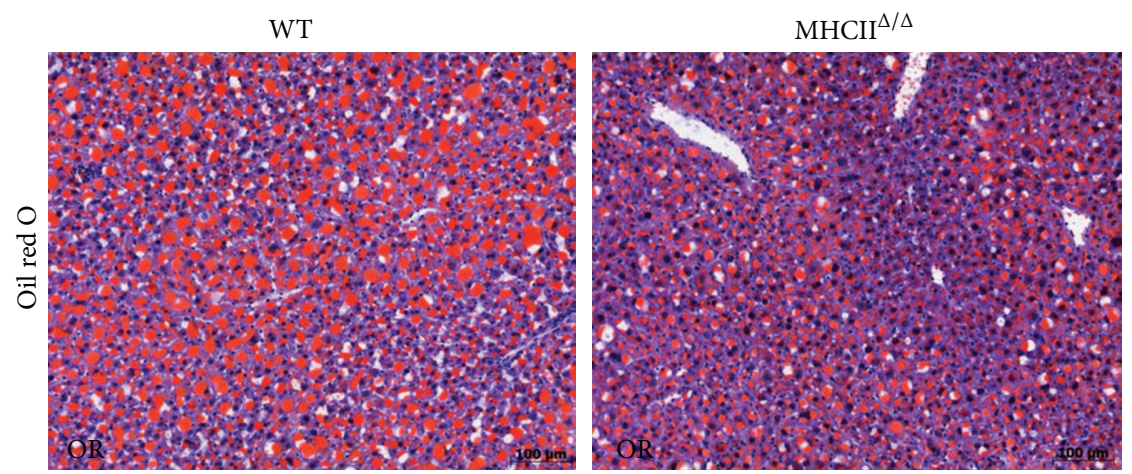

(a)
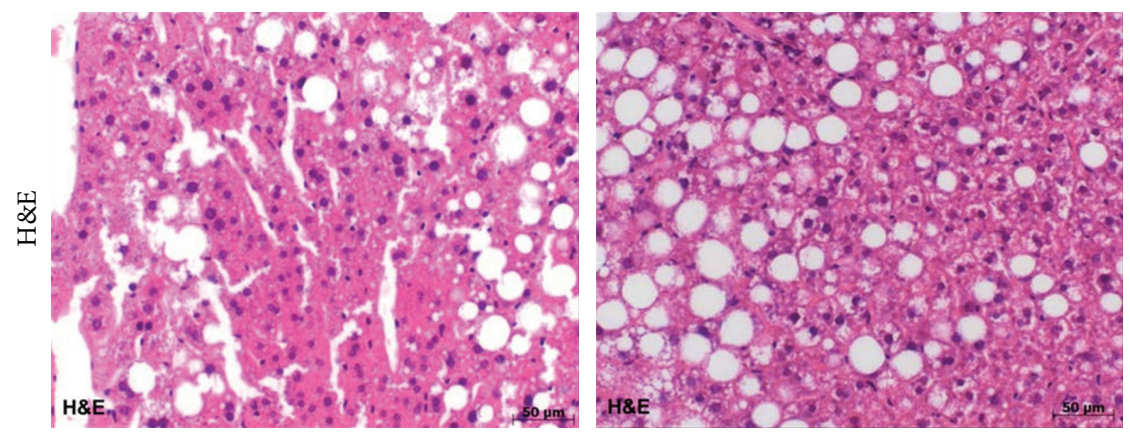

(b)
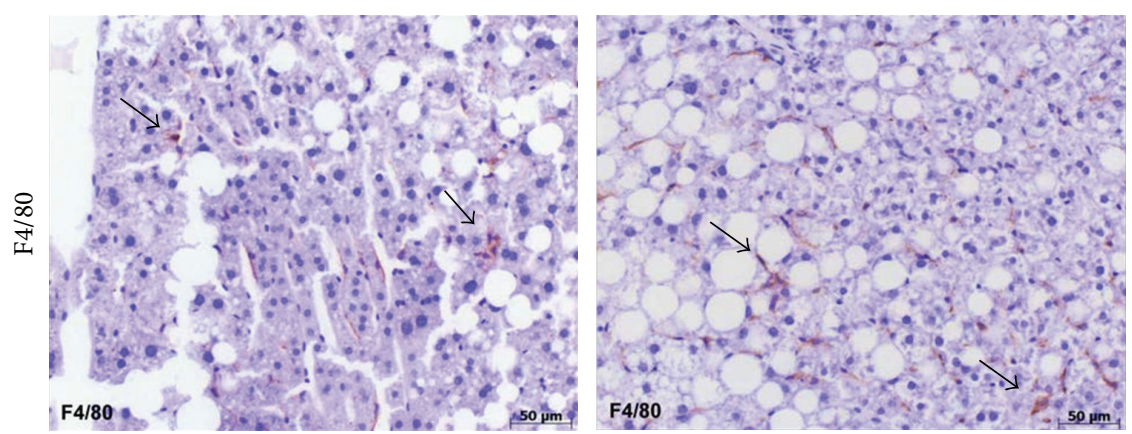

(c)

FIGURE 4: Effect of high-fat diet on liver histology in wild-type and $\mathrm{MHCII}^{\Delta / \Delta}$ mice. (a) Oil red O staining (red color represents the lipid accumulation). (b) Hematoxylin and eosin (H\&E) staining. (c) F4/80 immunohistochemistry (macrophages were stained in brown: arrows).

4 hours. After several washings with PBS, liver samples were dehydrated and parafinated for histological analysis.

2.4. Histology. Parafinated liver samples were sliced $(4 \mu \mathrm{m})$ and stained according to a standard technique with hematoxylin and eosin (H\&E) using routine methods. To study the fibrosis formation, $0.1 \%$ sirius red was used to stain collagen I, III, and bile pigment using a protocol described elsewhere [20]. For the histological samples, photos were taken with an AXIO Imager M1 with fluo-Axiocam MRm and color Axiocam MRc cameras (Carl Zeiss AG, Oberkochen, Germany). Images were treated by Axiovision release 4.8.2. We then quantified the fibrotic area by assessing the ratio of the red-stained area (fibrosis) to the total area, the vascular luminal area being subtracted if present, using Photoshop
(Adobe Systems, Mountain View, USA) in five images per section of the sample ( $10 \mathrm{x}$ magnification).

Immunohistochemistry by glial fibrillary acidic protein (GFAP) stain was performed by the subsequent incubations of the slices with rabbit anti-GFAP primary antibody (Dako, Glostrup, Denmark) diluted in normal goat serum for overnight at $4^{\circ} \mathrm{C}$, then with goat anti-rabbit coupled with Alexa Fluor 568 (Life Technologies, Carlsbad, USA) for 30 minutes in the dark at room temperature. Immunostained sections were then counterstained with $4^{\prime}, 6$-diamidino-2phenylindole (DAPI), embedded with mowiol and analyzed using the Zeiss microscope.

2.5. Plasma Parameters and Liver Lipids Analysis. Total plasma ALT and AST were measured by the Roche/Hitachi 


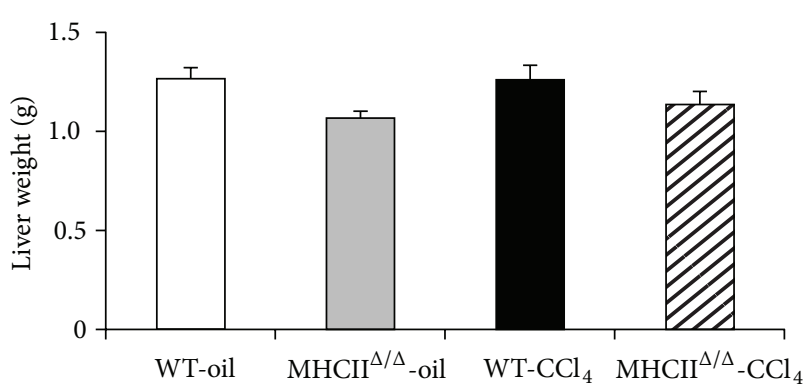

(a)

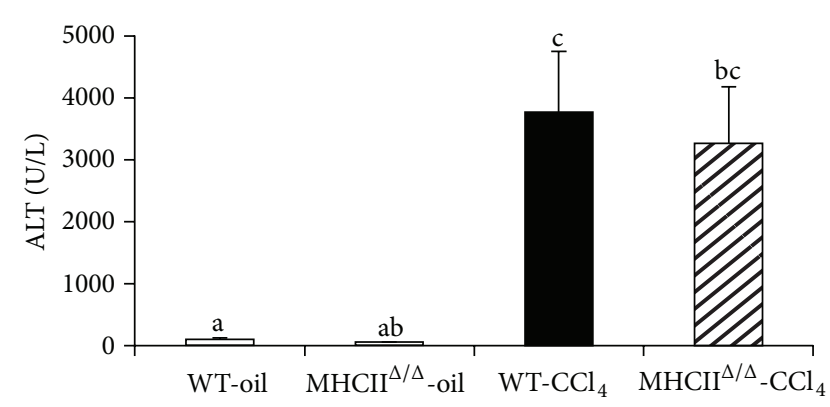

(c)

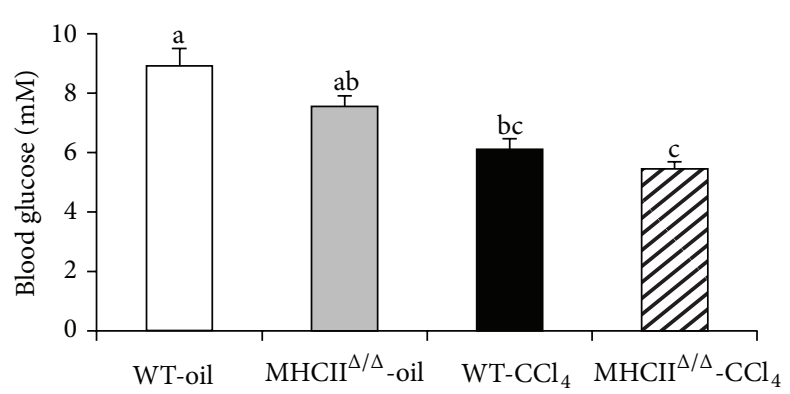

(b)

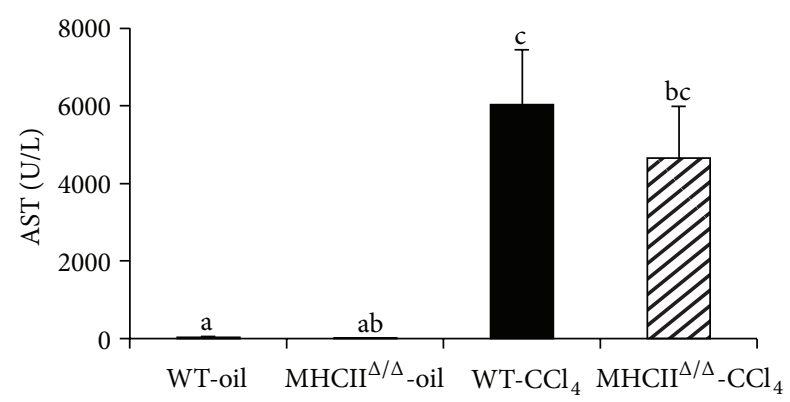

(d)

FIGURE 5: Effect of 4-week $\mathrm{CCl}_{4}$ treatment on liver and blood glucose in wild-type and $\mathrm{MHCII}^{\Delta / \Delta}$ mice. Open bars represent oil-treated wild-type (WT-oil), closed bars $\mathrm{CCl}_{4}$-treated wild-type (WT-CCl 4 ), gray bars oil-treated $\mathrm{MHCII}^{\Delta / \Delta}$ mice, and semiclosed bars CCl ${ }_{4}$-treated $\mathrm{MHCII}^{\Delta / \Delta}$ mice (wild-type oil: $n=7, \mathrm{MHCII}^{\Delta / \Delta}$ oil: $n=5$, wild-type $\mathrm{CCl}_{4}: n=11, \mathrm{MHCII}^{\Delta / \Delta} \mathrm{CCl}_{4}: n=9$ ). Data are presented as mean \pm SEM. (a) Liver weight. (b) Fasting blood glucose decreased after the $\mathrm{CCl}_{4}$ treatment in both groups. (c), (d) Strong increase in fasting plasma ALT and AST was observed after the $\mathrm{CCl}_{4}$ treatment. ${ }^{\mathrm{a}, \mathrm{b}, \mathrm{c}} \mathrm{P}<0.05$, ANOVA and Tukey Kramer HSD test. Different letters indicate the significant difference between groups.

912 instrument with the commercial kits mentioned earlier. Insulin was measured by a Mouse Insulin ELISA kit (Mercodia, Uppsala, Sweden). Plasma active Plasminogen activator inhibitor-1 (PAI-1) was also measured by an ELISA kit (Molecular Innovations Inc., Novi).

From the harvested liver samples, total lipids were extracted using a modified Folch method [21, 22]. For the measurement of hepatic TG content, total lipid extract was subjected to SPE columns (Interchim, Montluçon, France) to separate TG $[23,24]$. TG were then mixed with a chloroformtriton $\mathrm{X}(1 \%)$ solution and dried under $\mathrm{N}_{2}$ gas. TG were thus dissolved into water and the content of TG was measured by the use of the Wako Chemical kit.

2.6. Genotyping and Real-Time Polymerase Chain Reaction $(P C R)$. Ear DNA was extracted by the hotSHOT protocol [25]. Genotyping was performed according to Jackson laboratory's protocol (http://jaxmice.jax.org/strain/003584.html). Briefly, 2 sets of primers were used for the mutated gene (oIMR1020: 5'-Cgg AAg TgC TTg ACA TTg g-3', oIMR1021:5' -gTA TTg ACC gAT TCC TTg Cg-3') and wildtype gene (oIMR1273; $5^{\prime}$-AAC CTT CAg gAT CTg TgA TCC3', oIMR1274; 5' -gTg gCT gTT gCC TTA AgA CC-3'). After PCR cycles, samples were loaded onto $2 \%$ agarose gels and the mutated band (209 bp) as well as the wild-type band (178 bp) was monitored.
Total RNA was extracted from tissues according to the phenol-chloroform extraction protocol in Tri Reagent (Molecular Research Center, Inc., Cincinnati, USA) [26]. cDNA was created by a reverse transcription of $2 \mu \mathrm{g}$ of total RNA using Superscript II Transcriptase from Invitrogen (Life Technologies, Carlsbad, USA) according to the manufacturer's protocol. Real-time RT-PCR was performed on Applied Biosystems' 7000 Sequence Detection System (Life Technologies, Carlsbad). Twenty-time diluted cDNA samples and $0.3 \mu \mathrm{M}$ forward and reverse primers (Microsynth $\mathrm{AG}$, Balgach, Switzerland) in a final $10 \mu \mathrm{L}$ volume were reacted in the following PCR cycle conditions: 10 minutes at $95^{\circ} \mathrm{C}$ followed by 40 cycles of 15 seconds at $95^{\circ} \mathrm{C}$ and 1 minute at $60^{\circ} \mathrm{C}$. Each sample was analyzed in duplicate using the DeltaDeltaCt method [27]. $\beta 2$ microglobulin ( $\beta 2 \mathrm{M})$ was used as a housekeeping gene to normalize the expression of each gene.

2.7. Statistics. All data are shown in mean \pm standard error of the mean (SEM). Two groups were compared by Student $t$-test. Four groups were compared by one-way analysis of variance (ANOVA) and once it reached the significance $(F<0.05)$, a post hoc test (Tukey Kramer HSD test) was performed. The statistical analyses were performed by use of the JMP software (SAS Institute Inc., Cary). 


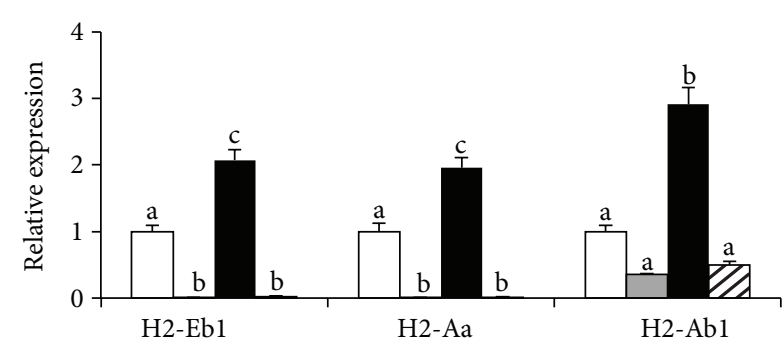

(a)

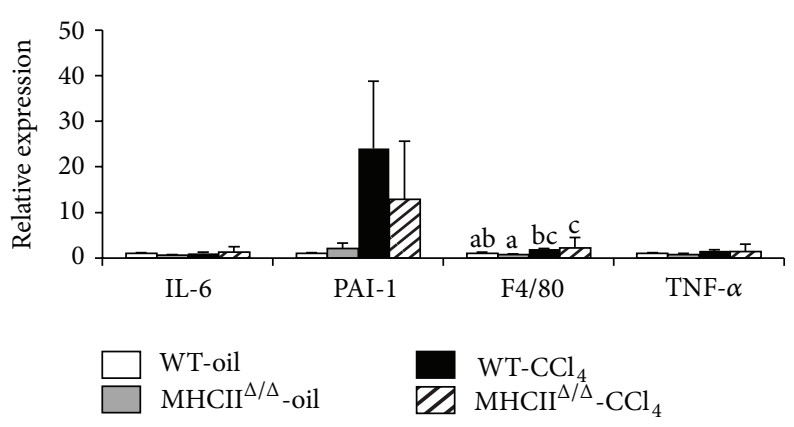

(c)

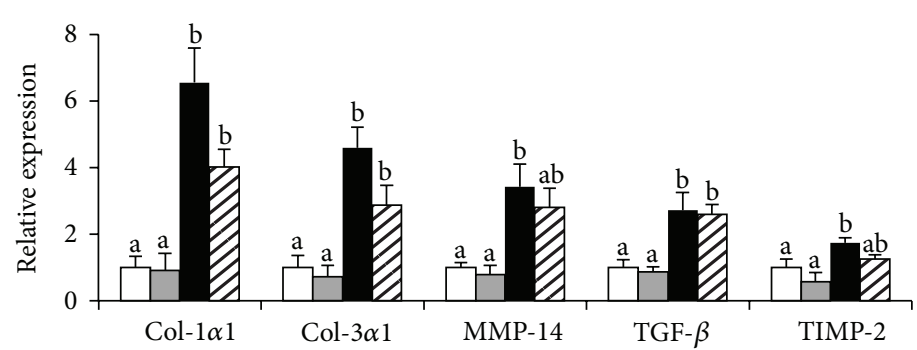

(b)

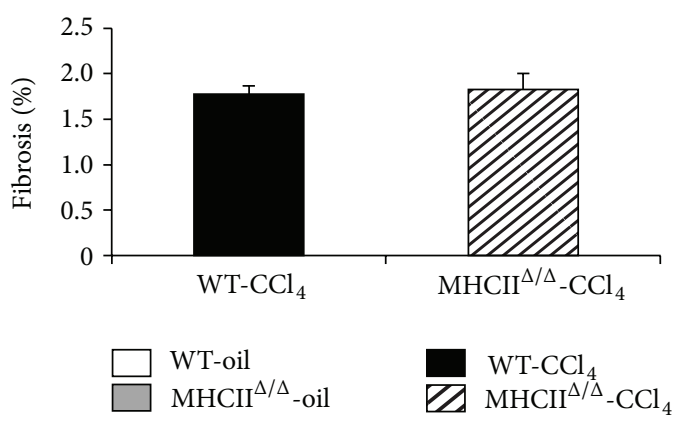

(d)

FIGURE 6: Effect of 4-week $\mathrm{CCl}_{4}$ treatment on hepatic gene expression and fibrosis in wild-type and $\mathrm{MHCII}^{\Delta / \Delta}$ mice. Open bars represent oiltreated wild-type (WT-oil, $n=7)$, closed bars $\mathrm{CCl}_{4}$-treated wild-type (WT-CCl $\left.{ }_{4}, n=11\right)$, gray bars oil-treated MHCII ${ }^{\Delta / \Delta} \mathrm{mice}\left(\mathrm{MHCII}^{\Delta / \Delta}\right.$ oil, $n=5)$, semiclosed bars $\mathrm{CCl}_{4}$-treated $\mathrm{MHCII}^{\Delta / \Delta}$ mice $\left(\mathrm{MHCII}^{\Delta / \Delta}-\mathrm{CCl}_{4}, n=9\right)$. Data are presented as mean \pm SEM. (a) MHC II gene expression. (b) Gene expression related to fibrosis formation. (c) Gene expression related to inflammation. (d) No difference in fibrosis (\%) between groups treated by $\mathrm{CCl}_{4}$. The percentage was determined based on the sirius red staining $\left(5\right.$ pictures $/ \mathrm{mice}, \mathrm{WT}-\mathrm{CCl} \mathrm{Cl}_{4}: n=5$, $\left.\mathrm{MHCII}^{\Delta / \Delta}-\mathrm{CCl}_{4}: n=8\right) .{ }^{\mathrm{a}, \mathrm{b}, \mathrm{c}} P<0.05$, ANOVA and Tukey Kramer HSD test. Different letters indicate the significant difference between groups.

\section{Results}

3.1. Validation of the Mouse Model. The $\mathrm{MHCII}^{\Delta / \Delta}$ mice were originally created by the laboratory of Dr. Christophe Benoist (Institut de Génétique et de Biologie Moléculaire et Cellulaire, Illkirch, France). These mice lack the major genes of MHC II pathway and present very low counts of CD4+ T lymphocytes in the thymus and spleen [19]. The detailed genetic modification and their phenotype have been published [19]. These mice have been backcrossed with C57B6/J strain at Jackson laboratory. After purchasing the mice from Jackson laboratory, we crossed them with C57B6/J mice to obtain control wild-type animals. In this model, the PCR for detecting the knockout allele showed a clear band at $209 \mathrm{bp}$. The quantitative PCR analysis showed no or very low expression of the genes of the MHC II pathway (Figure 1).

\subsection{Effect of High-Fat Diet on Inflammatory Status in} $\mathrm{MHCII}^{\Delta / \Delta}$ Mice. Both wild-type and $\mathrm{MHCII}^{\Delta / \Delta}$ mice similarly gained body weight after 4-month high-fat diet (Figure 2). Liver weight was also similar in both groups. Plasma glucose and insulin concentrations were comparable between groups. As expected, both groups had similar glucose tolerance after the long-term high-fat diet. The liver TG content was also comparable between groups (Figure 3). Oil red $\mathrm{O}$ staining confirmed this result (Figure 4). Plasma ALT and AST levels were equally high after the high-fat diet in two groups (Figure 3), suggesting similar liver functions after the high-fat diet.

To study the inflammatory status of the liver after the long-term high-fat diet feeding, we have performed $\mathrm{H} \& \mathrm{E}$ staining and F4/80 for macrophages staining. We observed positive markers of F4/80 and similar lipid droplet morphology in both groups (Figure 4). The expression of genes related to inflammation such as IL-6, TNF- $\alpha$, PAI-1, and F4/80 was not different between groups (Figure 3 ). The mRNA levels of fibrosis markers such as collagen type $1 \alpha 1$ (Col-1 $\alpha 1)$ and matrix metalloproteinase-14 (MMP-14) were also comparable. We also measured active PAI-1 concentration in the plasma (Figure 3). Again no difference was observed between wild-type and $\mathrm{MHCII}^{\Delta / \Delta}$ mice. All together, blocking the MHC II pathway did not affect the hepatic inflammation induced by the high-fat diet in mice.

\subsection{Effect of $\mathrm{CCl}_{4}$ Injection on the Formation of Hepatic} Fibrosis in $\mathrm{MHCII}^{\Delta / \Delta}$ Mice. We next studied the development of hepatic fibrosis. To this end, we treated wild-type and $\mathrm{MHCII}^{\Delta / \Delta}$ mice with $\mathrm{CCl}_{4}$ during 4 weeks. The treatment resulted in a significant decrease of glycemia and a significant increase of ALT and AST in both groups (Figure 5). No difference in liver weight was observed. The $\mathrm{CCl}_{4}$ injections also highly induced the expression of MHC II genes in wild-type mice, while $\mathrm{MHCII}^{\Delta / \Delta}$ mice had no induction 

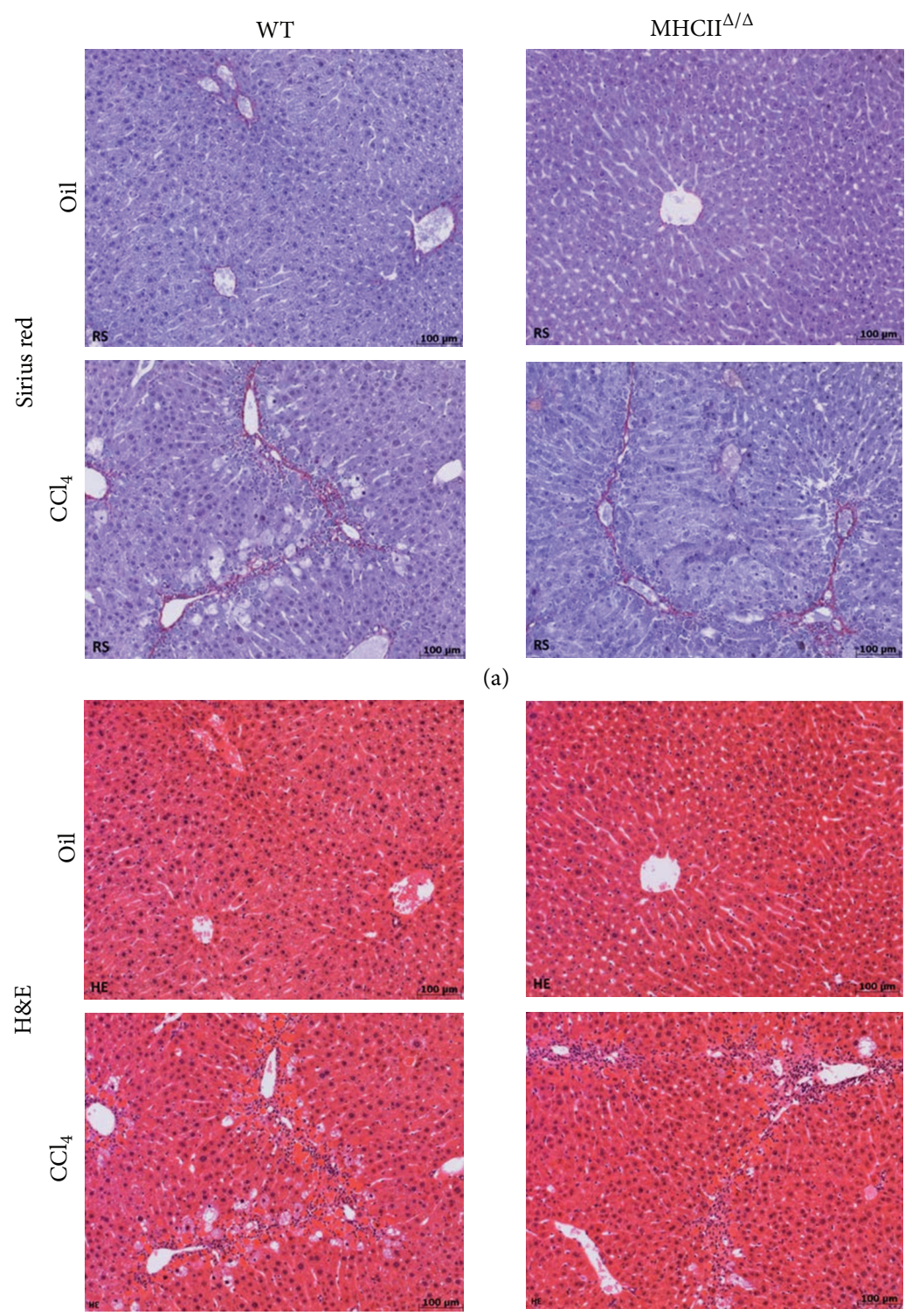

(a)
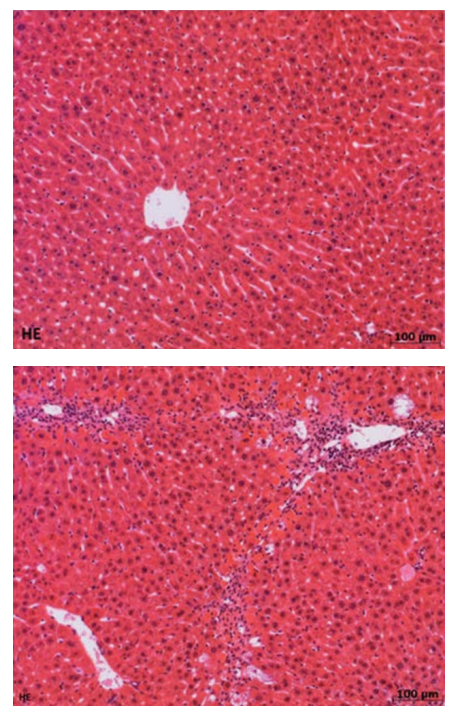

(b)

FIGURE 7: Effect of 4-week $\mathrm{CCl}_{4}$ treatment on liver histology in wild-type and $\mathrm{MHCII}^{\Delta / \Delta}$ mice. (a) Sirius red staining for collagen. The red staining represents fibrotic area. (b) Hematoxylin and eosin (H\&E) staining.

of these genes, as expected (Figure 6). Genes related to the fibrosis formation such as Col-1 $\alpha 1$, Col- $3 \alpha 1$, and transforming growth factor- $\beta$ (TGF- $\beta$ ) significantly increased in both groups after the $\mathrm{CCl}_{4}$ injections compared to the oil-injected groups. The genes such as MMP-14 and tissue inhibitor of metalloproteinase-2 (TIMP-2) were also highly induced after $\mathrm{CCL}_{4}$ treatment in wild-type mice: however, the induction was somewhat blunted in $\mathrm{MHCII}^{\Delta / \Delta}$ mice.

The liver histology was analyzed using sirius red staining for fibrosis formation. No positive staining was detected in oil-treated groups. The level of positive staining in $\mathrm{CCl}_{4}{ }^{-}$ treated livers was quantified using Photoshop. We detected a comparable level of fibrosis between groups treated by $\mathrm{CCl}_{4}$ (Figures 6 and 7). H\&E staining also showed inflammatory signs in the liver treated by $\mathrm{CCl}_{4}$ (Figure 7). Again, no remarkable difference was observed between wild-type and $\mathrm{MHCII}^{\Delta / \Delta}$ mice. The staining by F $4 / 80$ showed a remarkable infiltration of macrophages in the livers of mice treated by $\mathrm{CCl}_{4}$, but, again, no difference was observed between wildtype and $\mathrm{MHCII}^{\Delta / \Delta}$ mice (Figure 8). We further stained stellate cells by GFAP. Interestingly we detected only one positive staining out of 13 in wild-type mice while we found 7 positive stainings out of 9 samples in $\mathrm{MHCII}^{\Delta / \Delta}$ mice (Figure 9).

\section{Discussion}

The present study demonstrated that the MHC II pathway is not implicated in the development of hepatitis when induced 


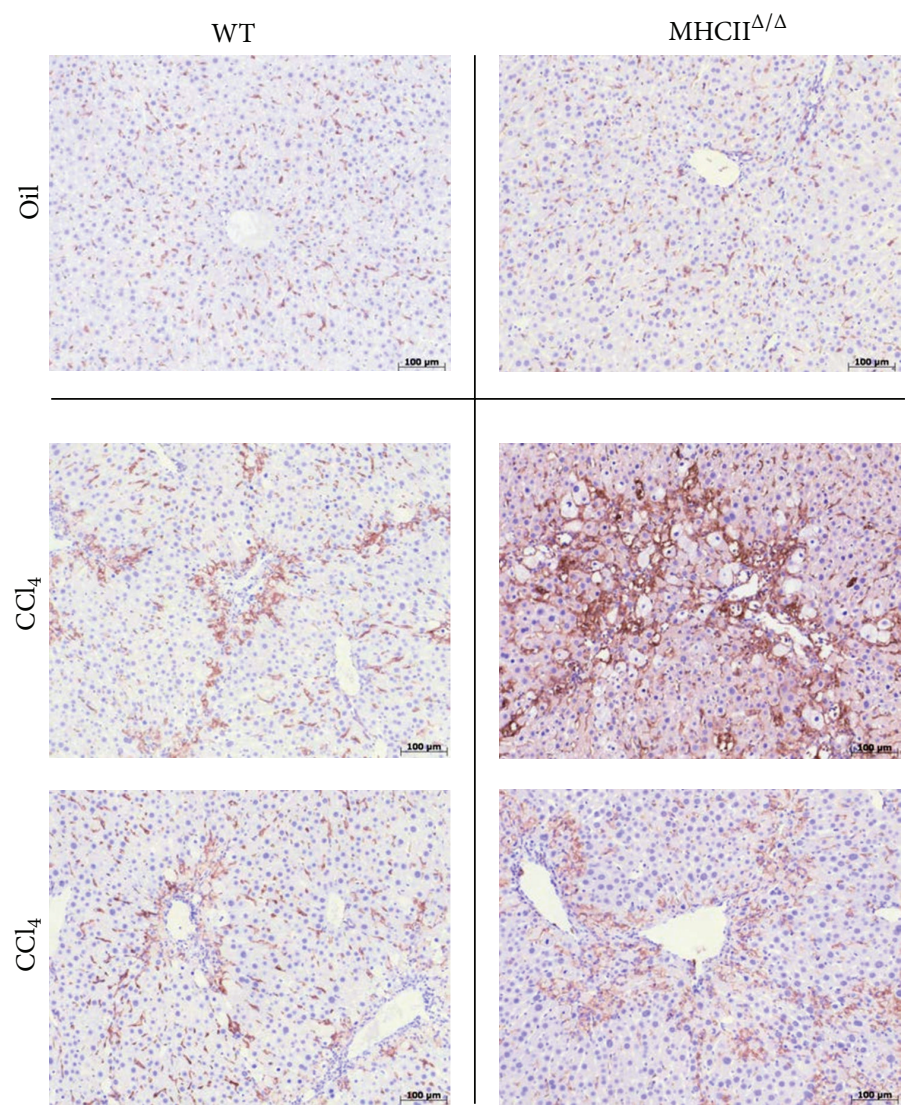

FIGURE 8: Effect of 4-week $\mathrm{CCl}_{4}$ treatment on macrophage staining in wild-type and $\mathrm{MHCII}^{\Delta / \Delta}$ mice. Macrophage staining (F4/80) showed a strong inflammation in both groups treated by $\mathrm{CCl}_{4}$.

by a long-term high-fat diet. We had taken the approach of the high-fat diet to mimic our obesogenic lifestyle that is known to contribute to the nonalcoholic steatohepatitis (NASH). It is also strongly supported that feeding laboratory animals with high-caloric diets such as a high-fat diet can induce NASH [28-30]. As proposed in the pathophysiology of NASH, the "two-hit theory" could also explain the progression of hepatic steatosis to NASH in our experimental model. The first hit is an infiltration of fat into the hepatocytes (hepatic steatosis) and the second hit is characterized by an infiltration of immune cells such as monocytes and lymphocytes because of abnormal oxidative stress [31, 32]. Our mice having undergone a 4-month high-fat diet presented a high amount of fat content in the liver in both groups (first hit). Extensive high-fat diet feeding then resulted in a comparable increase of hepatic inflammation/damage in two groups, judged by macrophage infiltration (second hit). These data suggest that the long-term high-fat diet induced both hepatic steatosis and NASH; however, blocking the MHC II pathway had no influence on the development of hepatic steatosis and NASH in these mice.

Our long-term high-fat diet also increased the level of ALT and AST in both groups compared to the normal range of ALT and AST generally observed in chow-fed mice (15-80 U/L and 40-120 U/L, respectively, in our laboratory measurements). This result strongly suggests that the modification in MHC II gene expression affected neither ALT nor AST levels, consistent to their comparable liver histology between groups. It has been, however, suggested that some alleles in MHC II pathway were associated with a severity of NAFLD and ALT, but not AST levels, in a Turkish population [33]. In this study, the investigators could not assess a presence of NASH in the population. To our knowledge, this study is the only report suggesting an association between the HLA allele and NAFLD in general population. Many other studies have shown a connection between the HLA allele and plasma ALT or NASH severity in hepatitis C patients or in patients with a drug-induced liver injury $[3,6,8,9,34,35]$. Therefore, MHC II pathway might have a bigger importance to the development of NASH caused by viral infections or drugs than by diet-induced NAFLD.

Secondly, we focused on the chemically induced fibrosis in mice lacking all conventional MHC II genes. As mentioned before, some HLA alleles are associated with an increased susceptibility to develop a drug-induced liver injury. The $\mathrm{CCl}_{4}$ treatment strikingly increased the plasma level of ALT, AST, and the degree of hepatic fibrosis in both genotypes. The genes of MHC II pathway were also highly induced by $\mathrm{CCl}_{4}$ treatment in wild-type mice, indicating the upregulation of the pathway upon the treatment. Despite the lack of the upregulation of the pathway, the $\mathrm{MHCII}^{\Delta / \Delta}$ mice equally developed a hepatic fibrosis. These data strongly indicate 


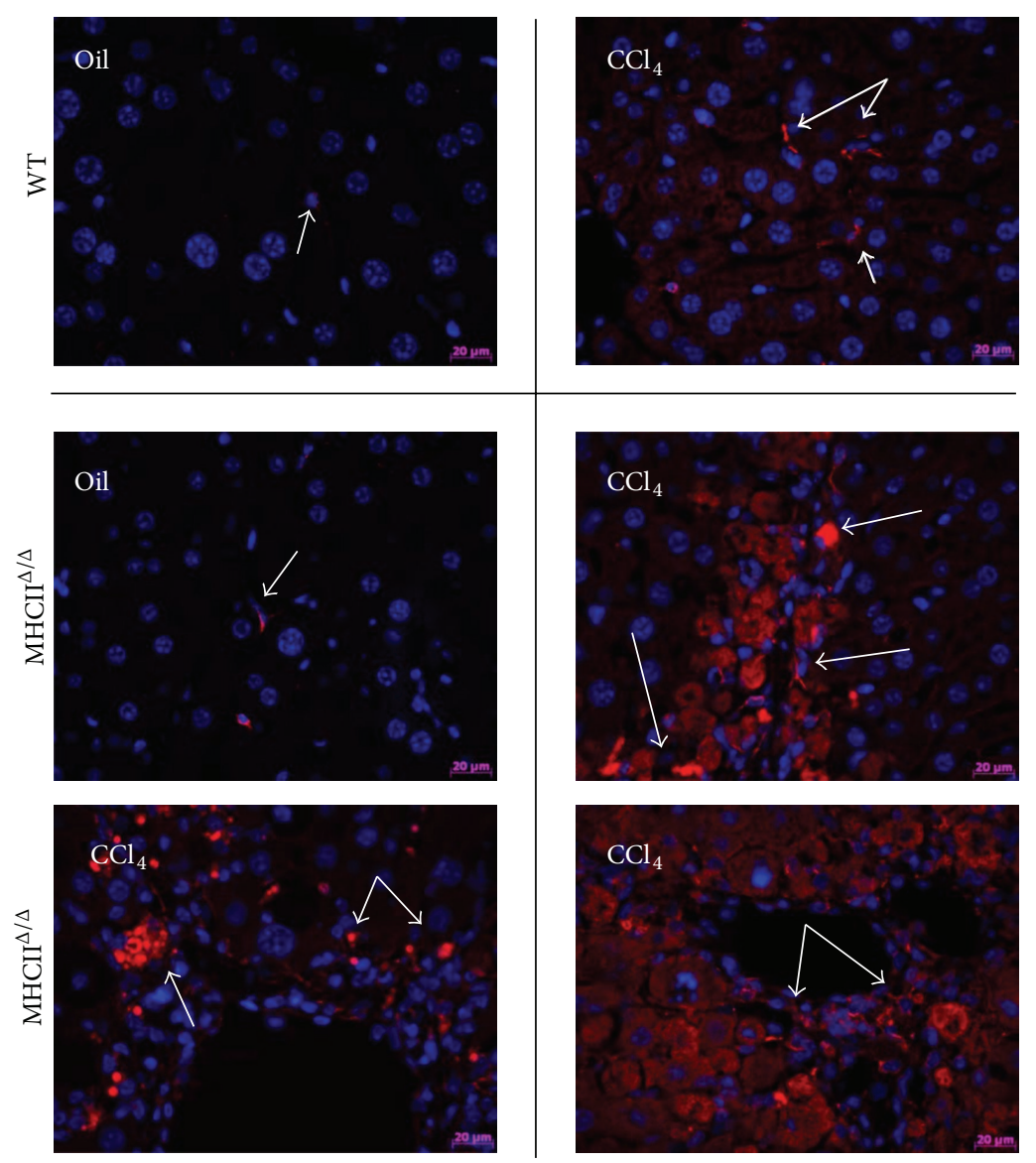

FIGURE 9: Effect of 4-week $\mathrm{CCl}_{4}$ treatment on GFAP staining in wild-type and $\mathrm{MHCII}^{\Delta / \Delta}$ mice. Glial fibrillary acidic protein (GFAP; white arrows) was stained in red. Increased positive staining was observed in $\mathrm{CCl}_{4}$-treated $\mathrm{MHCII}^{\Delta / \Delta}$ mice. Blue: DAPI staining.

that the MHC II pathway is not required for the development of hepatic fibrosis, at least in the mouse model of $\mathrm{CCl}_{4}$ induced hepatic fibrosis.

Although the major genes implicated in the formation of fibrosis, namely, Col- $1 \alpha 1$, Col- $3 \alpha 1$, and TGF- $\beta$ were similarly upregulated in the groups of mice treated by $\mathrm{CCl}_{4}$, the induction of some genes such as TIMP-2 and MMP-14 tended to be lower in the $\mathrm{MHCII}^{\Delta / \Delta}$ mice compared to the wild-type mice. TIMP-2 expression has been observed during the early stages of fibrogenesis induced by a porcine serum [36]. We thought that the deletion of MHC II genes might have affected the progression of fibrosis at an earlier time point. In our study, we had tested different periods of injection of $\mathrm{CCl}_{4}(2-$, 4-, 6-, and 8-week treatment) in these mice. In any condition tested, we did not observe a significant difference in the gene expression related to the fibrosis formation (data not shown). We also confirmed these results by liver histology. This again supports the idea that the MHC II pathway is not interfering with the development of hepatic fibrosis induced by $\mathrm{CCl}_{4}$.

Although histological data suggested that there was no difference in the severity of the fibrosis between groups treated by $\mathrm{CCl}_{4}$, we found a profound increase in the hepatic stellate cells (HSC) staining only in the group of $\mathrm{MHCII}^{\Delta / \Delta}$ mice treated by $\mathrm{CCl}_{4}$. HSC are nonparenchymal cells in the liver and are known to play an important role in fibrosis and tissue repairing [37]. Upon the quiescent HSC activation, they are converted into myofibroblasts, which are responsible for the production of extracellular matrices [38]. The importance of the HSC activation in fibrogenesis was recently reported by Puche et al. [39]. They have elegantly created a transgenic mouse model whose proliferating HSC were selectively killed. By use of the model, Puche et al. demonstrated that these mice had reduced fibrotic area upon $\mathrm{CCl}_{4}$ treatment compared to their genetically controlled counterparts. This signifies the important role of HSC in the development of hepatic fibrosis.

In our study, despite the hyperactivation of HSC in $\mathrm{MHCII}^{\Delta / \Delta}$ mice, the fibrosis formation was strictly comparable between groups. We do not know the exact cause and effect of this HSC induction in $\mathrm{MHCII}^{\Delta / \Delta}$ mice treated by $\mathrm{CCl}_{4}$. We have observed that the expression of the genes of the MHC II pathway was very high in HSC fraction when we separated different cellular types in the liver (hepatocytes, HSC, Kupffer cells, and endothelial cells) (unpublished data). This suggests that the HSC could play an important role for the MHC II reaction. We do not know, however, whether the absence of the pathway in $\mathrm{MHCII}^{\Delta / \Delta}$ mice might have affected the HSC proliferation upon $\mathrm{CCl}_{4}$ stimulation. 
On the other hand, the activation of HSC during the development of fibrosis is suggested to be transient [40]. We did not identify when HSC started to be activated in $\mathrm{MHCII}^{\Delta / \Delta}$ mice during the $\mathrm{CCl}_{4}$ treatment. Whether this hyperactivation of HSC has compensated the lack of the MHC II pathway and contributed to the fibrosis formation needs to be further addressed.

The present study clearly demonstrated that the lack of MHC II pathway affected neither NASH induced by highfat diet nor fibrosis induced by $\mathrm{CCl}_{4}$ in mice. Despite a large number of publications implying the association between the alleles in the MHC II pathway and drug-induced liver injury and hepatitis $\mathrm{C}$ in humans, this study clearly indicated that the MHC II pathway is not required in the development of $\mathrm{NASH}$ and fibrosis at least in mice.

\section{Conflict of Interests}

G. Willemin, C. Roger, A. Bauduret, and K. Minehira have no conflict of interests.

\section{Authors' Contribution}

K. Minehira contributed to the conception and design of the experiments. All in vivo experiments and tissue sampling were carried out in the animal facility of the Bugnon $7 / 9$, University of Lausanne, by G. Willemin and K. Minehira. Histological analysis was carried out by C. Roger. The remaining experiments, including any molecular and biochemical analyses, were performed by G. Willemin at the Department of Physiology, University of Lausanne. A. Bauduret contributed to the genotyping strategy. G. Willemin and K. Minehira participated in data analysis and interpretation. K. Minehira wrote the initial draft of the paper, and all authors contributed to its revisions and approved the final version.

\section{Acknowledgments}

The authors thank Mr. Thierry Bouduban and Mr. Francois Mange for technical support and Mr. Nicholas Broskey for suggestions. The authors thank the group of Professor Bernard Thorens for the donation of liver cellular fractions. The authors also thank the animal facility of Bugnon 7/9, University of Lausanne, and Mrs. Marianne Carrard (Mouse Metabolic Facility, University of Lausanne) for the Hitachi measurements. This study was supported by the Swiss National Science Foundation-Ambizione.

\section{References}

[1] J. S. Blum, P. A. Wearsch, and P. Cresswell, "Pathways of antigen processing," Annual Review of Immunology, vol. 31, pp. 443-447, 2013.

[2] N. A. Mitchison, “T-cell-B-cell cooperation," Nature Reviews Immunology, vol. 4, pp. 308-312, 2004.

[3] J. B. Singer, S. Lewitzky, E. Leroy et al., "A genome-wide study identifies HLA alleles associated with lumiracoxib-related liver injury," Nature Genetics, vol. 42, no. 8, pp. 711-714, 2010.
[4] P. Geusens and W. Lems, "Efficacy and tolerability of lumiracoxib, a highly selective cyclo-oxygenase-2 (COX2) inhibitor, in the management of pain and osteoarthritis," Therapeutics and Clinical Risk Management, vol. 4, no. 2, pp. 337-344, 2008.

[5] L. Laine, W. B. White, A. Rostom, and M. Hochberg, "COX-2 selective inhibitors in the treatment of osteoarthritis," Seminars in Arthritis and Rheumatism, vol. 38, no. 3, pp. 165-187, 2008.

[6] P. I. Pillans, R. A. Ghiculescu, G. Lampe, R. Wilson, R. Wong, and G. A. Macdonald, "Severe acute liver injury associated with lumiracoxib," Journal of Gastroenterology and Hepatology, vol. 27, no. 6, pp. 1102-1105, 2012.

[7] R. A. Moore, S. Derry, and H. J. McQuay, "Cyclo-oxygenase-2 selective inhibitors and nonsteroidal anti-inflammatory drugs: balancing gastrointestinal and cardiovascular risk," BMC Musculoskeletal Disorders, vol. 8, article 73, 2007.

[8] M. I. Lucena, M. Molokhia, Y. Shen et al., "Susceptibility to amoxicillin-clavulanate-induced liver injury is influenced by multiple HLA class i and II alleles," Gastroenterology, vol. 141, no. 1, pp. 338-347, 2011.

[9] R. J. Andrade, M. I. Lucena, A. Alonso et al., "HLA class II genotype influences the type of liver injury in drug-induced idiosyncratic liver disease," Hepatology, vol. 39, no. 6, pp. 1603$1612,2004$.

[10] G. M. Hirschfield, X. Liu, C. Xu et al., "Primary biliary cirrhosis associated with HLA, IL12A, and IL12RB2 variants," The New England Journal of Medicine, vol. 360, no. 24, pp. 2544-2555, 2009.

[11] K. Wakabayashi, Z. X. Lian, Y. Moritoki et al., "IL-2 receptor $\alpha-/-$ mice and the development of primary biliary cirrhosis," Hepatology, vol. 44, no. 5, pp. 1240-1249, 2006.

[12] J. Irie, Y. Wu, L. S. Wicker et al., "NOD.c3c4 congenic mice develop autoimmune biliary disease that serologically and pathogenetically models human primary biliary cirrhosis," Journal of Experimental Medicine, vol. 203, no. 5, pp. 1209-1219, 2006.

[13] S. El-Ghaiesh, J. P. Sanderson, J. Farrell et al., "Characterization of drug-specific lymphocyte responses in a patient with druginduced liver injury," Journal of Allergy and Clinical Immunology, vol. 128, no. 3, pp. 680-683, 2011.

[14] Y. Baba and K. Doi, "MHC class II-related genes expression in porcine-serum-induced rat hepatic fibrosis," Experimental and Molecular Pathology, vol. 77, no. 3, pp. 214-221, 2004.

[15] Y. Baba, K. Saeki, T. Onodera, and K. Doi, "Serological and immunohistochemical studies on porcine-serum-induced hepatic fibrosis in rats," Experimental and Molecular Pathology, vol. 79, no. 3, pp. 229-235, 2005.

[16] Z. M. Younossi, M. Stepanova, M. Afendy et al., "Changes in the prevalence of the most common causes of chronic liver diseases in the United States from 1988 to 2008," Clinical Gastroenterology and Hepatology, vol. 9, no. 6, pp. 524.el-530.el, 2011.

[17] G. Vernon, A. Baranova, and Z. M. Younossi, "Systematic review: the epidemiology and natural history of non-alcoholic fatty liver disease and non-alcoholic steatohepatitis in adults," Alimentary Pharmacology and Therapeutics, vol. 34, no. 3, pp. 274-285, 2011.

[18] J. S. Delgado, "Evolving trends in nonalcoholic fatty liver disease," European Journal of Internal Medicine, vol. 19, no. 2, pp. 75-82, 2008.

[19] L. Madsen, N. Labrecque, J. Engberg et al., "Mice lacking all conventional MHC class II genes," Proceedings of the National 
Academy of Sciences of the United States of America, vol. 96, no. 18, pp. 10338-10343, 1999.

[20] R. L. DeLellis and M. C. Bowling, "The use of sirius red and congo red staining in routine histopathology," Human Pathology, vol. 1, no. 4, p. 655, 1970.

[21] J. Folch, M. Lees, and G. H. S. Stanley, "A simple method for the isolation and purification of total lipides from animal tissues," The Journal of biological chemistry, vol. 226, no. 1, pp. 497-509, 1957.

[22] F. Snyder and N. Stephens, "A simplified spectrophotometric determination of ester groups in lipids," Biochimica et Biophysica Acta, vol. 34, pp. 244-245, 1959.

[23] G. C. Burdge, P. Wright, A. E. Jones, and S. A. Wootton, "A method for separation of phosphatidylcholine, triacylglycerol, non-esterified fatty acids and cholesterol esters from plasma by solid-phase extraction," The British Journal of Nutrition, vol. 84, no. 5, pp. 781-787, 2000.

[24] G. T. Y. Choi, M. Casu, and W. A. Gibbons, "N.m.r. lipid profiles of cells, tissues and body fluids: neutral, non-acidic and acidic phospholipid analysis of Bond Elut chromatographic fractions," Biochemical Journal, vol. 290, part 3, pp. 717-721, 1993.

[25] G. E. Truett, P. Heeger, R. L. Mynatt, A. A. Truett, J. A. Walker, and M. L. Warman, "Preparation of PCR-quality mouse genomic dna with hot sodium hydroxide and tris (HotSHOT)," BioTechniques, vol. 29, no. 1, pp. 52-54, 2000.

[26] P. Chomczynski and N. Sacchi, "The single-step method of RNA isolation by acid guanidinium thiocyanate-phenol-chloroform extraction: twenty-something years on," Nature Protocols, vol. 1, no. 2, pp. 581-585, 2006.

[27] J. H. Schefe, K. E. Lehmann, I. R. Buschmann, T. Unger, and H. Funke-Kaiser, "Quantitative real-time RT-PCR data analysis: current concepts and the novel "gene expression's C T difference" formula," Journal of Molecular Medicine, vol. 84, no. 11, pp. 901-910, 2006.

[28] C. Z. Larter and M. M. Yeh, "Animal models of NASH: getting both pathology and metabolic context right," Journal of Gastroenterology and Hepatology, vol. 23, no. 11, pp. 1635-1648, 2008.

[29] I. Kiki, B. Z. Altunkaynak, M. E. Altunkaynak, O. Vuraler, D. Unal, and S. Kaplan, "Effect of high fat diet on the volume of liver and quantitative feature of Kupffer cells in the female rat: a stereological and ultrastructural study," Obesity Surgery, vol. 17, no. 10, pp. 1381-1388, 2007.

[30] N. Rafiq and Z. M. Younossi, "Effects of weight loss on nonalcoholic fatty liver disease," Seminars in Liver Disease, vol. 28, no. 4, pp. 427-433, 2008.

[31] O. F. W. James and C. P. Day, "Non-alcoholic steatohepatitis (NASH): a disease of emerging identity and importance," Journal of Hepatology, vol. 29, no. 3, pp. 495-501, 1998.

[32] W. Youssef and A. J. McCullough, "Diabetes mellitus, obesity, and hepatic steatosis," Seminars in Gastrointestinal Disease, vol. 13, no. 1, pp. 17-30, 2002.

[33] M. Celikbilek, H. Selcuk, and U. Yilmaz, "A new risk factor for the development of non-alcoholic fatty liver disease: HLA complex genes," Turkish Journal of Gastroenterology, vol. 22, pp. 395-399, 2011.

[34] C. Renou, P. Halfon, S. Pol et al., "Histological features and HLA class II alleles in hepatitis $C$ virus chronically infected patients with persistently normal alanine aminotransferase levels," Gut, vol. 51, no. 4, pp. 585-590, 2002.
[35] M. Thursz, R. Yallop, R. Goldin, C. Trepo, and H. C. Thomas, "Influence of MHC class II genotype on outcome of infection with hepatitis C virus," The Lancet, vol. 354, no. 9196, pp. 21192124, 1999.

[36] Y. Hasegawa-Baba and K. Doi, "Changes in TIMP-1 and -2 expression in the early stage of porcine serum-induced liver fibrosis in rats," Experimental and Toxicologic Pathology, vol. 63, no. 4, pp. 357-361, 2011.

[37] S. L. Friedman, "Hepatic stellate cells: protean, multifunctional, and enigmatic cells of the liver," Physiological Reviews, vol. 88, no. 1, pp. 125-172, 2008.

[38] T. Knittel, L. Müller, B. Saile, and G. Ramadori, "Effect of tumour necrosis factor- $\alpha$ on proliferation, activation and protein synthesis of rat hepatic stellate cells," Journal of Hepatology, vol. 27, no. 6, pp. 1067-1080, 1997.

[39] J. E. Puche, Y. A. Lee, J. Jiao et al., "A novel murine model to deplete hepatic stellate cells uncovers their role in amplifying liver damage in mice," Hepatology, vol. 57, no. 1, pp. 339-350, 2013.

[40] S. Morini, S. Carotti, G. Carpino et al., "GFAP expression in the liver as an early marker of stellate cells activation," Italian Journal of Anatomy and Embryology, vol. 110, no. 4, pp. 193-207, 2005. 


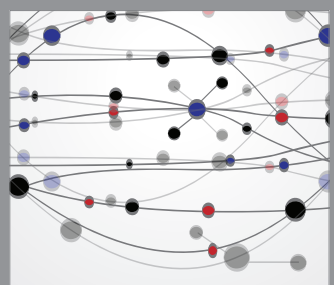

The Scientific World Journal
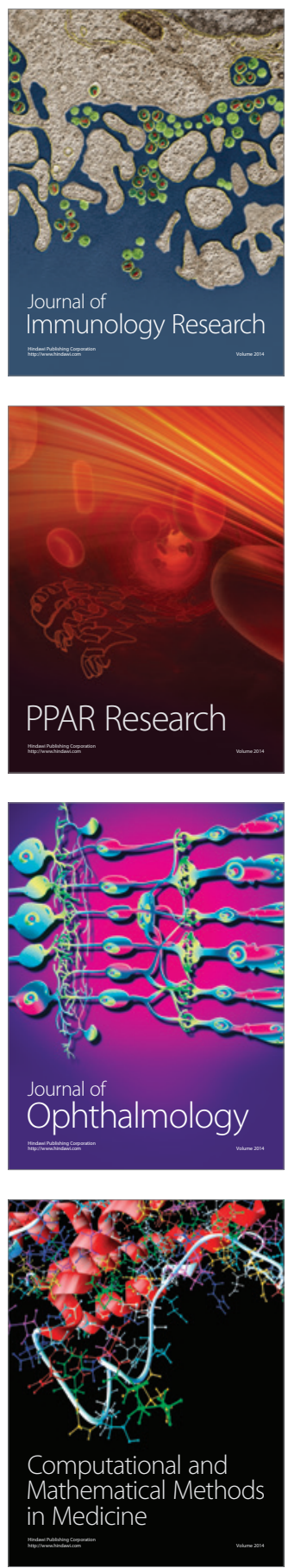

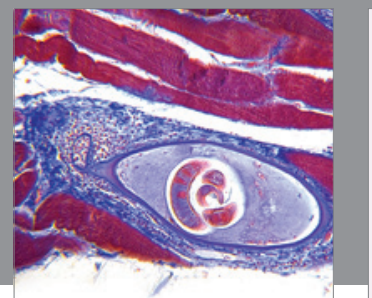

Gastroenterology

Research and Practice
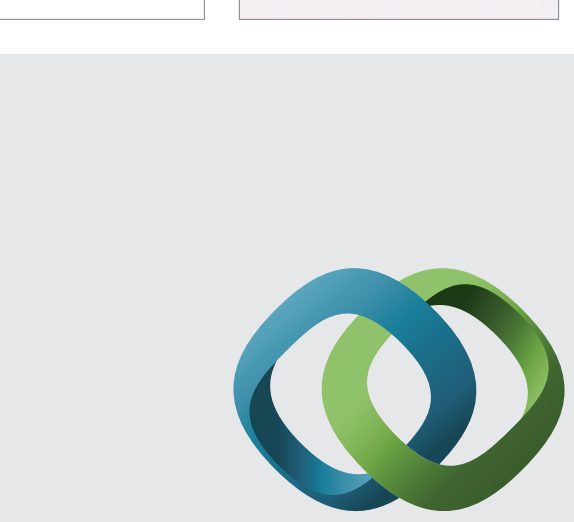

\section{Hindawi}

Submit your manuscripts at

http://www.hindawi.com
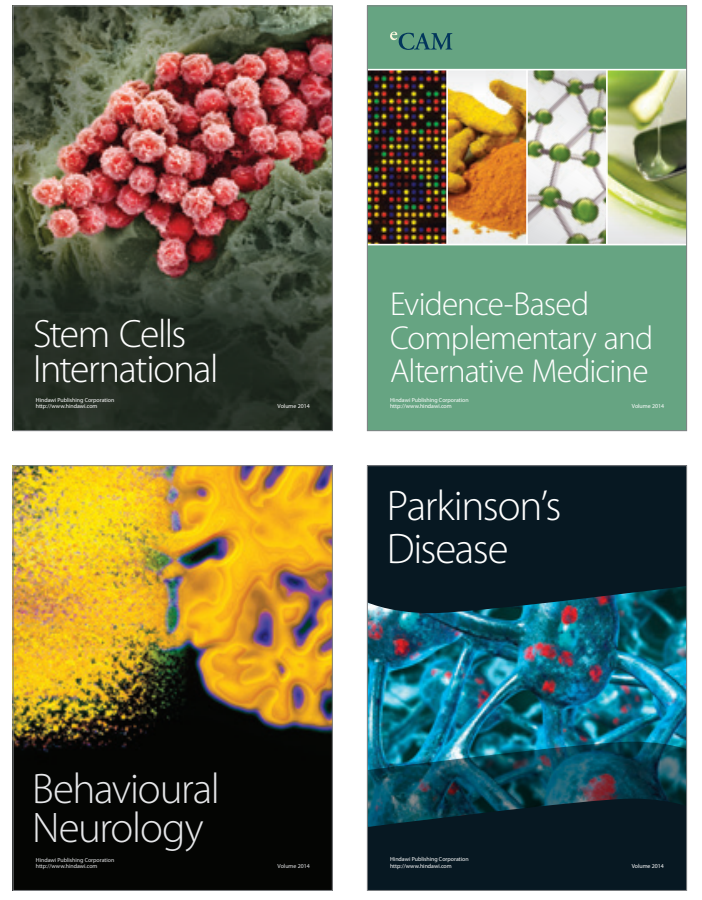
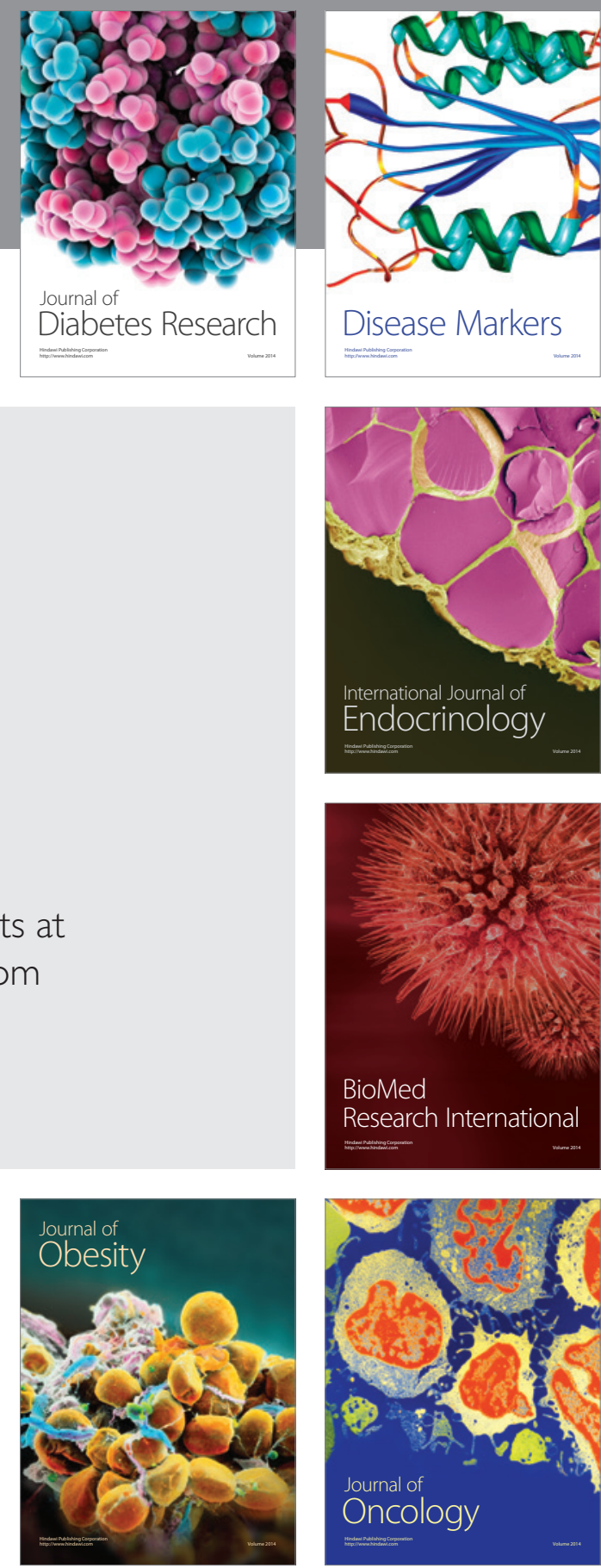

Disease Markers
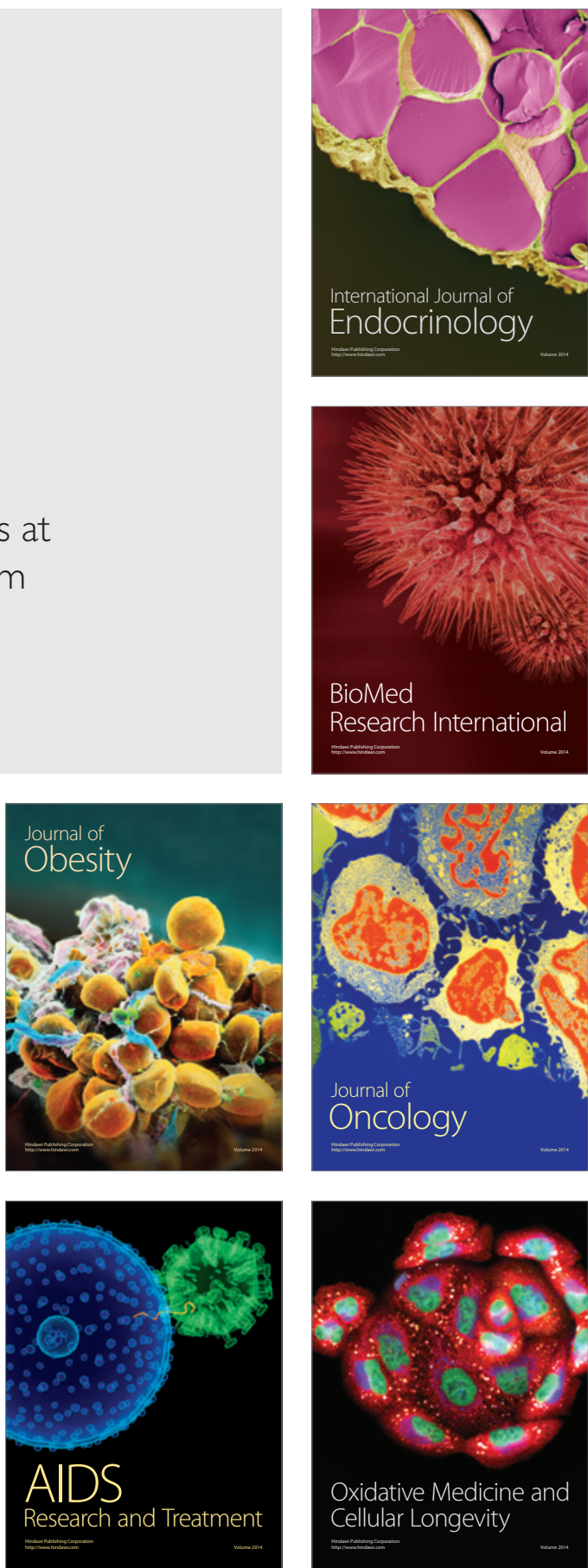